\title{
INFIL1D: A Quasi-Analytical Model for Simulating One- Dimensional, Constant Flux Infiltration
}
C. S. Simmons
T. J. McKeon

April 1984

Prepared for the U.S. Department of Energy under Contract DE-AC06-76RLO 1830

Pacific Northwest Laboratory Operated for the U.S. Department of Energy by Battelle Memorial Institute 


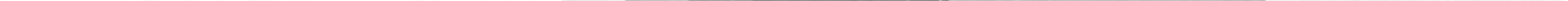


INFIL1D: A QUASI-ANALYTICAL MODEL FOR SIMULATING ONE-DIMENSIONAL, CONSTANT FLUX INFILTRATION

C. S. Simmons

T. J. McKeon

April 1984

Prepared for the U.S. Department of Energy under Contract DE-AC06-76RLO 1830

Pacific Northwest Laboratory Richland, Washington 99352 


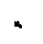




\section{ACKNOWLEDGMENTS}

This work, performed by Pacific Northwest Laboratory, was supported by the Department of Energy (DOE) Low-Level Waste Management Program, under Contract DE-AC06-76RLO 1830 with the U.S. Department of Energy. Pacific Northwest Laboratory is operated by Battelle Memorial Institute for the U.S. Department of Energy. 



\section{ABSTRACT}

The program INFILID is designed to calculate approximate wetting-front advance into an unsaturated, uniformly moist, homogeneous soil profile, under constant surface-flux conditions. The code is based on a quasi-analytical method, which utilizes an assumed invariant functional relationship between reduced (normalized) flux and water content. The code uses general hydraulic property data in tabular form to simulate constant surface-flux infiltration. 



\section{SUMMARY}

A computer program called INFIL1D was developed to calculate wetting-front movement into uniform soils under constant-flux infiltration conditions. The program is based on a quasi-analytical solution to the unsaturated flow equation, as derived by Perroux, Smiles and White (1981). Philip's (1973) concept of a flux-concentration relationship for the soil-water content profile was used to obtain an approximate solution. Plug flow occurring behind a wetting front when saturation of the soil surface takes place is also simulated. Upon surface saturation, a wetting front then advances by maintaining its shape invariantly ahead of a saturated plug flow zone, which enters the soil according to soil-water conservation constraints.

Hydraulic properties (diffusivity and conductivity) for an unsaturated soil are input in tabular form, and calculations are performed with intermediate values interpolated from the input table. This allows for use of entirely general property data.

The program uses a numerical integration over the involved water content range and is free of numerical difficulties often associated with finite difference methods. Special asymptotic integration features were included to treat singularities in the involved integral equations that describe wettingfront movement. Thus, the INFIL1D program is ideal for evaluating the accuracy of numerical infiltration simulations. To verify the program, a comparison with simulations of Haverkamp et al. (1977) was performed. The program was also tested with the original data obtained by Perroux, Smiles and White (1981). 


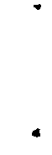




\section{CONTENTS}

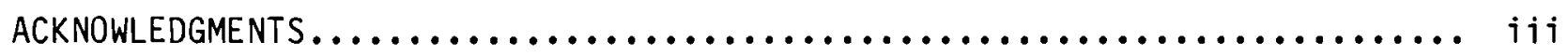

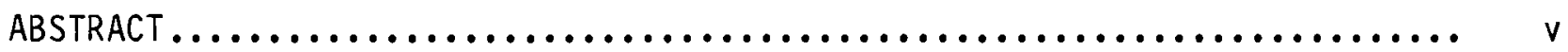

SUMMARY............................................... vii

INTRODUCTION................................................ 1

THEORY................................................... 3

QUASI-ANALYTICAL SOLUTION.................................. 5

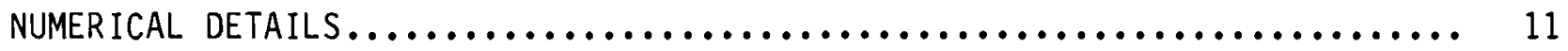

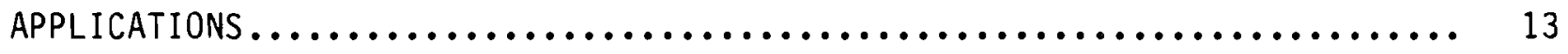

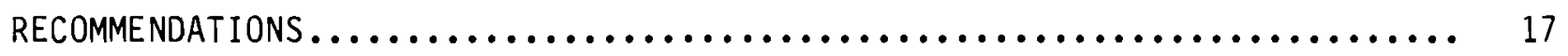

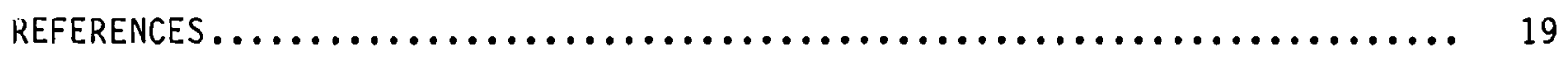

APPENDIX A: INFILID USER'S MANUAL.......................... A.1

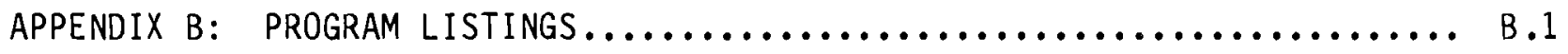

30209 C ix 


\section{FIGURES}

1 Infiltration Profiles at Times: $0.1,0.3,0.5$, and 0.8 hours for a Sand (Haverkamp et al. 1977). Surface $: 1$ ux equals

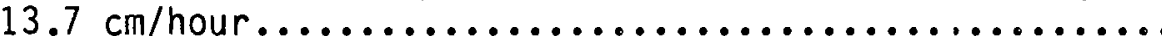

2. Infiltration Profiles at Reduced Times: $2.52,8.0,16.1 \times$

$10^{-7} \mathrm{~m}^{\star} \mathrm{m} / \mathrm{sec}$ for a Fine Sand (Perroux, Smiles and White 1981,

Figure 4$)$. Surface flux equals $2.8 \times 10^{-5} \mathrm{~m} / \mathrm{se}: \ldots \ldots \ldots \ldots \ldots \ldots \ldots \ldots$

3. Infiltration Profiles at Reduced Times: $2.52,8.0,16.1 \times$ $10^{-7} \mathrm{~m} \mathrm{~m}^{*} \mathrm{sec}$ for a Fine Sand (Perroux, Smiles and White 1981, Figure 4 . Surface flux equals $5.9 \times 10^{-5} \mathrm{~m} / \mathrm{sec} \ldots \ldots \ldots \ldots \ldots \ldots \ldots$

4. Horizontal Absorption Profiles for Values of Figure $3 \ldots \ldots \ldots \ldots$ 


\section{INTRODUCTION}

The calculation of detailed hourly or daily moisture balance within an unsaturated zone requires an accurate prediction of infiltration during rainfall events. Infiltration is usually estimated by numerically solving the nonlinear Richard's flow equation for wetting-front advance under either ponded or specified surface-flux boundary conditions. A specified surface-flux condition is generally the most appropriate description of a rainfall event.

Numerical control of wetting-front simulation, however, is perhaps the most difficult aspect of unsaturated zone computer modeling. The difficulty stems from the extreme changes that occur in hydraulic properties over the involved range of soil-water contents. Moreover, the difficulty is compounded because the hydraulic property dependence on water content may alter drastically with different soils.

Numerical simulations of wetting-front movement can exhibit severe oscillations that cause associated inaccuracy in profile flux, unless the equationsolving algorithm, spatial discretization, and time-step size are carefully coordinated. Therefore, accurate quasi-analytical solutions are needed, which can be employed to test, evaluate, and calibrate more general numerical codes.

Analytical and quasi-analytical solutions of Richard's equation for infiltration under constant surface head (ponding) conditions were those first extensively studied, as reviewed by Philip (1969). Philip's asymptotic series expansion in terms of the square root of time is the most well-known, quasianalytical solution. More exact analytical solutions are essentially impossible to find unless special, over-simplified hydraulic properties are assumed (Philip 1974). Tractable simplifications usually make a solution inappropriate for actual soil conditions.

To solve the infiltration problem under constant surface-flux conditions, and to simplify the flow equation, Philip (1973) introduced the concept of a flux-concentration relationship, based on equating relative flux to a function of relative water content, independent of depth. White, Smiles and Perroux 
(1979) demonstrated the validity of that concept for absorption (horizontal infiltration). A method for predicting vertical irfiltration based on the flux-concentration relationship was then described concisely by Perroux, Smiles and White (1981), in conjunction with supporting experimental justification.

This report discusses the computer model called INFIL1D, which was designed to implement the quasi-analytical method fresented by Perroux, Smiles and White (1981). Certain mathematical difficulties associated with singularities in the controlling integral equations, however, were not treated and accounted for by those authors. Those potential difficulties are considered in this report. Their method was further extended to include the situation when a saturated zone (plug flow) advances behind the unsaturated wetting front. Thus, surface-water content, which increases with time during infiltration, need not be restricted from reaching saturation as in the original derivation.

The INFIL1D code allows for use of completely general hydraulic properties (soil-water diffusivity and conductivity point dati.), and an arbitrary constant surface flux can be specified. Options for various limiting-case, fluxconcentration functions are also included. Although not an exact result, the quasi-analytical solution has proven very accurate. An extensive comparison of infiltration simulations presented by Haverkamp et al. (1977) was used to further demonstrate the program. 


\section{THEORY}

The partial differential equation (a nonlinear Fokker-Plank equation) that describes vertical water movement in an unsaturated soil is

$$
d \theta / d t=d / d z[D(\theta) d \theta / d z-K(\theta)]
$$

where $\theta$ is volumetric water content $\left(L^{3} / L^{3}\right) ; D(\theta)$ is soil-water diffusivity $\left(L^{2} / t\right) ; K(\theta)$ is. hydraulic conductivity $(L / t)$; and $z$ is depth $(L)$ defined as positive downward. (Here $d / d t$ and $d / d z$ denote partial derivatives.) Equation (1) is related to Richard's unsaturated flow equation through the definition of soil-water diffusivity

$$
D(\theta)=K(\theta) \mathrm{dh} / \mathrm{d} \theta
$$

where $h(\theta)$ is the soil-water pressure head (matric potential). The relationship between $h$ and $\theta$ is called the soil-water characteristic curve (moisture retention curve). Darcy's flux, denoted $V(\theta)$, as a functional of $\theta$, is

$$
V(\theta)=-D(\theta) d \theta / d z+K(\theta)
$$

The first term of Equation (3) is the moisture diffusion flux; the hydraulic conductivity term is the gravity component, which always moves downward.

Equation ( 1 ) is valid for all moisture-flow conditions only if $h(\theta)$ is unique and single-valued so that hysteresis behavior is excluded (i.e., Equation (1) applies to isothermal unsaturated flow in nonswelling soils). Equation (3), therefore, applies only when $\theta$ is less than the saturated value. Diffusivity is undefined (infinite) at saturated conditions. Darcy's law, when based on the pressure head gradient and hydraulic conductivity, however, remains applicable throughout all conditions. But for the single-flow process of infiltration into uniformly moist soil, Equation (1) still applies for hysteretic soils provided that the wetting-curve branch of a characteristic 
curve is used to define diffusivity. Also, a capillary fringe should not be present. Of course, hydraulic conductivity must be unique and the influence of soil-air movement must be negligible.

For horizontal absorption, the gravity term of Equation (3) vanishes, and Equation (1) becomes a nonlinear diffusion equatior. Absorption under constant water-content (or pressure head) conditions has been extensively studied by Philip (1969). The problem of absorption and infiltration under constant surface-flux conditions was only given emphasis more recently (Philip 1974; Perroux, Smiles and White 1981).

Under field conditions, infiltration is primarily controlled by surface flux that equals the rainfall rate. Not until the soil surface becomes saturated and the water ponds does a specified surface pressure head become the appropriate boundary condition. Prasad and Romkens (1982) described a model incorporating both of these stages of infiltration. However, if a soil surface crust controls the infiltration process, a flux boundary condition may remain appropriate for the entire time. The mathematical discussion presented here will follow this latter conceptualization. Smiles, Knight and Perroux (1982) have described absorption governed by a soil crust.

In the case of constant surface flux, the poncling pressure head must become positive and increase in time when that flus: exceeds saturated conductivity, Ks. Within a saturated zone, Equation (3) no longer holds, and the Darcy flux becomes

$$
V(\theta s)=-K s d h / d z+K s
$$

Supposing that $\theta$ does not deviate from saturation with time implies that the flux, $v$, is constant and so is the pressure head gradient. Pressure head, $h$,

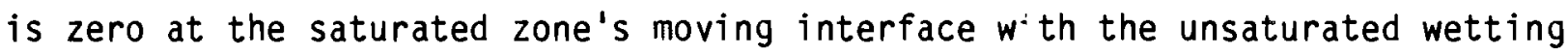
front. Thus, this boundary condition is clearly unlike that for constant head ponding conditions. 


\section{QUASI-ANALYTICAL SOLUTION}

The discussion is concerned with solving Equation (1) for infiltration under a constant surface-flux boundary condition. A homogeneous soil profile with initially uniform moisture content is assumed. As a consequence of the extreme nonlinearity, a general analytical solution of Equation (1) does not exist. However, Philip (1973) found an approximate, quasi-analytical method for describing infiltration by presuming existence of a flux-concentration relation as follows:

$$
F(\hat{\theta}, t)=(V(\theta)-K n) /\left(V_{0}-K n\right)
$$

where $\hat{\theta}=(\theta-\theta n) /\left(\theta_{0}-\theta_{n}\right)$ is the reduced water content, and $K n$ is $K(\theta n)$ for the initial water content $\theta n$. The surface-water content, which increases with time from the beginning of infiltration under the constant flux, Vo, is $\theta 0(t)$. Relevant initial and boundary conditions are

$$
\begin{aligned}
& \theta(z, 0)=\theta n, \quad z>0 \\
& \theta(0, t)=\theta 0(t), t>0 \\
& V(\theta)=V_{0}, z=0, t>0 .
\end{aligned}
$$

A function $F$ defined by Equation (4) would depend in general on the particular hydraulic properties $D(\theta)$ and $K(\theta)$. However, certain mathematical properties would be common to all such functions. For $0<\hat{\theta}<1, F$ would increase monotonically and satisfy $0<\hat{\theta} \leq F(\hat{\theta}, t)<1$. Philip identified an envelope for the possible $F$, based on special soil properties and absorption conditions. White, Smiles and Perroux (1979) reviewed the nature of those $F(\hat{\theta}, t)$ and indicated that the minimum (lower bound) is

$$
F(\hat{\theta}, t)=\hat{\theta}
$$


and the maximum (upper bound) is

$$
F(\hat{\theta}, t)=\sin \left[\frac{\pi}{2} \hat{\theta}^{\pi / 4}\right]
$$

Equation (5a) is associated with a delta-function diffusivity at $\theta 0$ and Equation (5b) with a constant value, both under conditions of constant $\theta 0$. An intermediate function $F$ for constant $D$ and $V_{0}$ was :ound to be approximated by

$$
F(\hat{\theta}, t)=\hat{\theta}^{2-4 / \pi}
$$

For horizontal absorption, White, Smiles and Perroux (1979) found that the wetting-front moisture profiles were not sensitive to the particular $F$ used when compared with the influence of uncertainty in $D(\theta)$. Perroux, Smiles and White (1981) extended the approximate solution method to vertical infiltration and suggested that Equation (5a) was adequate. A study by Haverkamp et a 1 . (1977) also supported the adequacy of Equation (5a) for describing wettingfront advance. Calculation of the precise $F$ by ineians of an iterative procedure was derived by Philip and Knight (1974). Apparently, any $F(\hat{\theta}, t)$ between the lower and upper bounds given by Equations (5a) and (5b) determines a first approximation for a wetting front. Moreover, any linear combination of $F$ functions (with positive multipliers summing to unity) is again a possible fluxconcentration relation. Smiles, Knight and Perrouk (1982) gave another $F$ function that best fits actual measurements for absorp:ion. Most importantly, however, the equations derived by Perroux, Smiles and White provide a simplified method for determining bounds on the wetting-front advance. In many cases those bounds may actually fall within experimental uncertainty and, therefore, constitute a sufficiently accurate description of ivetting-front movement.

The approximate quasi-analytical method based on an assumed known $F(\hat{\theta})$, which is independent of time, is derived again below and extended to include the situation when time exceeds a finite ponding time, Tp. A finite Tp occurs only when Vo exceeds the saturated hydraulic conductivity, Ks. The derived equations are the basis for the INFILID program. 
An equation for the wetting-front profile is obtained by substituting Equation (3) for flux into Equation (4) and by integrating for $z(\theta, t)$ as an explicit function of $\theta$. The resulting equation is

$$
\left(V_{0}-K_{n}\right)(z-Z s(t))=\int_{\theta}^{\theta_{0}(t)} G(\theta, \theta 0(t)) d \theta
$$

where we have defined

$$
G(\theta, \theta 0)=D(\theta) /\left[F(\hat{\theta})-(K(\theta)-K n) /\left(V_{0}-K n\right)\right]
$$

for $\theta n<\theta \leq \theta 0$. The function $Z s(t)$ is the location of maximum $\theta$ within the unsaturated zone. Letting Tp denote a finite time at which the soil surface becomes saturated, $\mathrm{Zs}(\mathrm{t})$ equals zero for $t<T p$. If $\theta 0(t)$ does not attain the saturated value $\theta s$ at any time, then $T p$ is infinite and $Z s(t)$ vanishes in Equation ( 7$)$. A finite Tp exists only when $V_{0}>K(\theta s)$, as will be demonstrated by obtaining the time when each $\theta_{0}$ is reached.

Equations for the unknown $\theta 0(t)$ and $Z s(t)$ are found by using the statement of soil-water conservation:

$$
d / d t \int_{\theta_{n}}^{\theta} z d \theta=V(\theta)-k n
$$

The constant surface-flux boundary condition then gives

$$
\int_{\theta_{n}}^{\theta_{0}(t)} z d \theta=\left(V_{0}-k n\right) t
$$


Equation (9) defines the total soil-water storage added to the profile after time $t$. Substitution of $z(\theta, t)$, from Equation (7), into Equation (9) and integration by parts yields:

$$
\left(V_{0}-K_{n}\right)^{2} t=\int_{\theta_{n}}^{\theta_{0}(t)}(\theta-\theta n) G(\theta, \theta 0(t)) d \theta
$$

Equation (10) determines time $t$ when each $\theta 0(t)$ is reached.

Certain mathematical properties of $G(\theta, \theta 0)$ for $\theta n<\theta<\theta 0<\theta$ s determine the behavior of wetting-front advance. Because $G(\theta, \theta 0)$ has a nonintegrable singularity at $\theta n$, then $z(\theta, t) \rightarrow+\infty$ as $\theta \rightarrow \theta n$, according to Equation (7). The integrand of Equation (10), however, is integrable near $\theta n$, because both $F(\hat{\theta})$ and $[K(\theta)-K n]$ are asymptotically proportional to $(\theta-\theta n)$ near $\theta n$. The program makes use of an asymptotic expression for $G(\theta, \theta 0)$ near $\theta$ n to calculate the integrals of Equations (7) and (10). The leading edge of a wetting front must therefore be calculated for a minimum water content, $\theta_{1}$, set arbitrarily above $\theta n$. The profile between $\theta_{1}$ and $\theta$ n can be macle a negligible 'tail', which constitutes an arbitrarily small storage quantity.

Two infiltration situations depending on the magnitude of Vo are identified as follows. These two cases determine the behavior of surface water content $\theta o(t)$ and depend on the $\mathrm{Ks}$ value.

Case Vo<Ks: There exists a maximum $\theta 0$, which is called $\theta \mathrm{m}$, such that $V_{0}=K(\theta m) . G(\theta, \theta m)$ has a nonintegrable singularity at $\theta m$, so that $z(\theta, t) \rightarrow+\infty$ for every $\theta$ when $\theta 0 \rightarrow \theta \mathrm{m}$. Moreover, Tp determined by Equation (10) for $\theta 0=\theta \mathrm{m}$ is infinite. Note that $\theta \mathrm{m}$ equal to $\theta s$ is not excluded as a possibility. Thus, in this case the time to reach maximum surface-water content is infinite, and the advancing front extends to infinity as that maximum is approached.

Case Vo>ks: Now $\theta m$ equals $\theta s$, but $G(\theta, \theta s)$ does not have a singularity for $\theta n<\theta \leq \theta s$. This means that a finite Tp determined by Equation (10) with $\theta 0=\theta s$ exists. Therefore when $t \leq T p$, the front location determined by Equation ( 7 ) is everywhere finite. 
When $V_{0}>k s$, the extent of the saturated zone $Z s(t)$ is determined from Equation (9) for $\theta 0(t)=\theta$ s when $t \geq T p$. The water storage satisfies:

$$
\begin{aligned}
\int_{\theta_{n}}^{\theta_{s}} z d \theta & =\int_{\theta_{n}}^{\theta_{n}} Z s d \theta+\int_{\theta_{n}}^{\theta_{n}}(z-Z s) d \theta \\
& =(\theta s-\theta n) Z s+\left(V_{0}-K n\right) T p
\end{aligned}
$$

By combining Equations (9) and (11), Zs is given by

$$
Z s(t)=\left(V_{0}-K n\right)(t-T p) /(\theta s-\theta n)
$$

for $t \geq T p$; and $Z s$ vanishes otherwise.

When the wetting-front movement has been determined from Equations (7) and (10), the infiltration flux for each depth and time can be found directly from the defined flux-concentration relationship of Equation (4). Accuracy of the quasi-analytical wetting front is checked in the INFIL1D program by computing the storage integral, Equation (9). Also, the program is designed to calculate horizontal absorption by removing the gravitational flow term from the Darcy flux. Resulting equations, which are simpler, were derived by White, Smiles and Perroux (1979).

For a wetting-front advance that approximates that of absorption, the water-content profiles can be scaled by introducing reduced variables:

$$
\begin{aligned}
& Z=\left(V_{0}-K n\right) z \\
& T=\left(V_{0}-K n\right)^{2} t
\end{aligned}
$$

White, Smiles and Perroux (1979) and Perroux, Smiles and White (1981) used these reduced variables. 
.

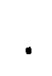


NUMERICAL DETAILS

In order that the wetting front be well-defined, the functions $F(\hat{\theta})$ and $K(\theta)$ need to satisfy a compatibility condition:

$$
F[(\theta-\theta n) /(\theta m-\theta n)] \geq(K(\theta)-K n) /(K(\theta m)-K n)
$$

when $\theta$ is between $\theta n$ and $\theta m$. Then

$$
F(\hat{\theta})>(K(\theta)-K n) /\left(V_{0}-K n\right)
$$

for $\theta n<\theta \leq \theta 0<\theta m$, since

$$
F(\hat{\theta})>F[(\theta-\theta n) /(\theta m-\theta n)]
$$

and $V_{0} \gg K(\theta m)$. Inequality, Equation (14), is only a sufficient condition so that $G(\theta, \theta 0)$ has no singularity for $\theta n<\theta \leq \theta 0<\theta m$. The program INFILID checks directly that the necessary inequality, Equation (15), holds over the integration interval of Equation (10). If the inequality, Equation (14), holds at specified tabulated values of $K(\theta)$, and $K(\theta)$ is represented as a convex function over the $\theta$ intervals between the specified values, then Equation (15) will hold. A function is strictly convex when, a linear interpolation between two function values is greater than the actual intermediate function value. For instance, a linear or exponential interpolation over an interval defines a convex function. Note that all properly defined $F$ are concave functions, and the required inequality may hold for an interpolation that is not necessarily convex.

Because Equation (10) is an implicit function for $\theta 0(t)$ at each $t$, an iterative method is used in INFIL1D to calculate $\theta 0$ at specified times. Iterations are performed until to has a time within a user-specified tolerance. Wetting-front location is then calculated for the associated approximate өo. The entire method, of course, is quasi-analytical because required integrals are numerically evaluated. An IMSL (1980) integration routine is 
employed by INFIL1D, but any other adequately accurate algorithm could be applied instead. To estimate required integrals, the code uses logrithmiclinear interpolation of hydraulic property values between the tabular input. This means that hydraulic properties are represented as exponential curves between the specified values. 


\section{APPLICATIONS}

The INFILID code was compared with several other published results. The first comparison was made with results published by Haverkamp et al. (1977). Those authors present both experimental data and simulations based on a variety of finite difference numerical methods. The hydraulic properties of a sand were used [Haverkamp et al. 1977, Equation (12)]. Initial water content was $0.1 \mathrm{~cm}^{3} / \mathrm{cm}^{3}$, and the $\mathrm{flux}$ was $13.7 \mathrm{~cm} /$ hour. Simulation results shown in Figure 1 compare quite well with both the experimental and numerical results presented by Haverkamp et a1. (1977, Figure 2).

The Haverkamp et a1. (1977) example represents a case for which Vo is much less than saturated conductivity, $\mathrm{Ks}$, equal to $34 \mathrm{~cm} / \mathrm{hour}$. For this case, the infiltration does not behave as absorption. Equation (10) gave better estimates of the surface water content than those obtained with Parlange's method, as discussed by Haverkamp et a1. (1977)

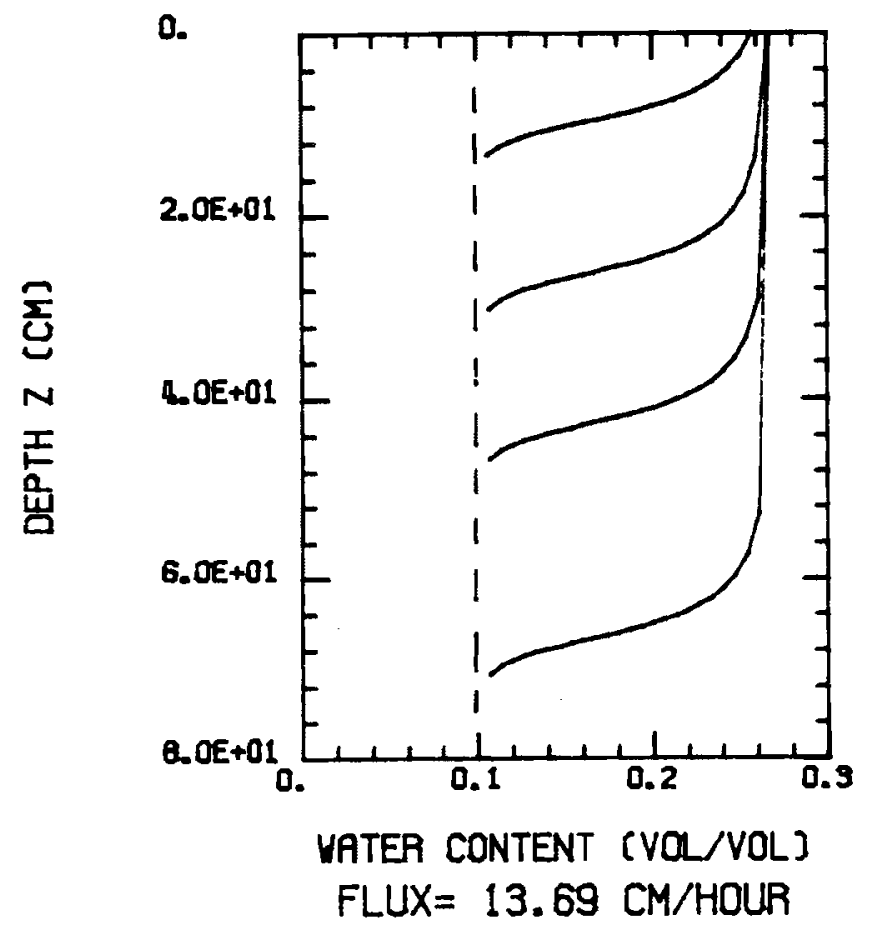

FIGURE 1. Infiltration Profiles at Times: $0.1,0.3,0.5$, and 0.8 Hours for a Sand (Haverkamp et al. 1977). Surface flux equals $13.7 \mathrm{~cm} /$ hour. 
A second comparison was made using the result:s published by Perroux, Smiles and White (1981). The soil type considered was Bungendore fine sand. Hydraulic properties of the sand were taken from figures given in that paper and from the diffusivity data given earlier by Whi":e, Smiles and Perroux (1979). The sand's initial water content was $0.01 \mathrm{~m}^{3} / \mathrm{m}^{3}$. Three comparisons were made: one with a flux $2.8 \times 10^{-5} \mathrm{~m} / \mathrm{sec}$, another with a flux $5.9 \times$ $10^{-5} \mathrm{~m} / \mathrm{sec}$, and a third absorption simulation repeated with the larger flux. The results are given in Figures 2, 3, and 4 in terms of reduced depth $Z$ and time $T$, Equations (13a) and (13b).

Figure 3, for flux $5.9 \times 10^{-5} \mathrm{~m} / \mathrm{sec}$, shows gond agreement the with results of Perroux, Smiles and White (1981, Figure 4). Those shown in Figure 2 for flux $2.8 \times 10^{-5} \mathrm{~m} / \mathrm{sec}$, however, do not compare as well. The calculated front has not moved as far down as that presented by Perroux, Smiles and White

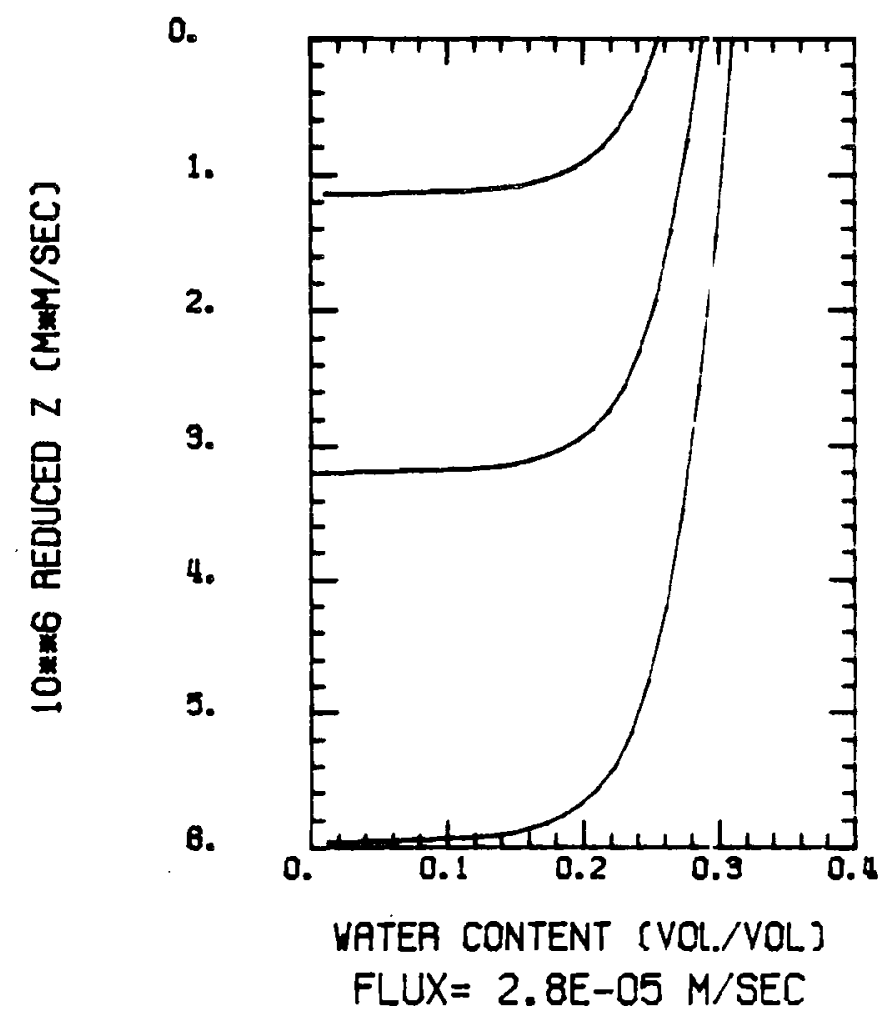

FIGURE 2. Infiltration Profiles at Reduced Tines: $2.52,8.0,16.1 \times$ $10^{-7} \mathrm{~m}^{\star} \mathrm{m} / \mathrm{sec}$ for a Fine Sand (Perrosx. Smiles and White 1981, Figure 4). Surface flux equals $2.8 \times 10^{-5} \mathrm{~m} / \mathrm{sec}$. 


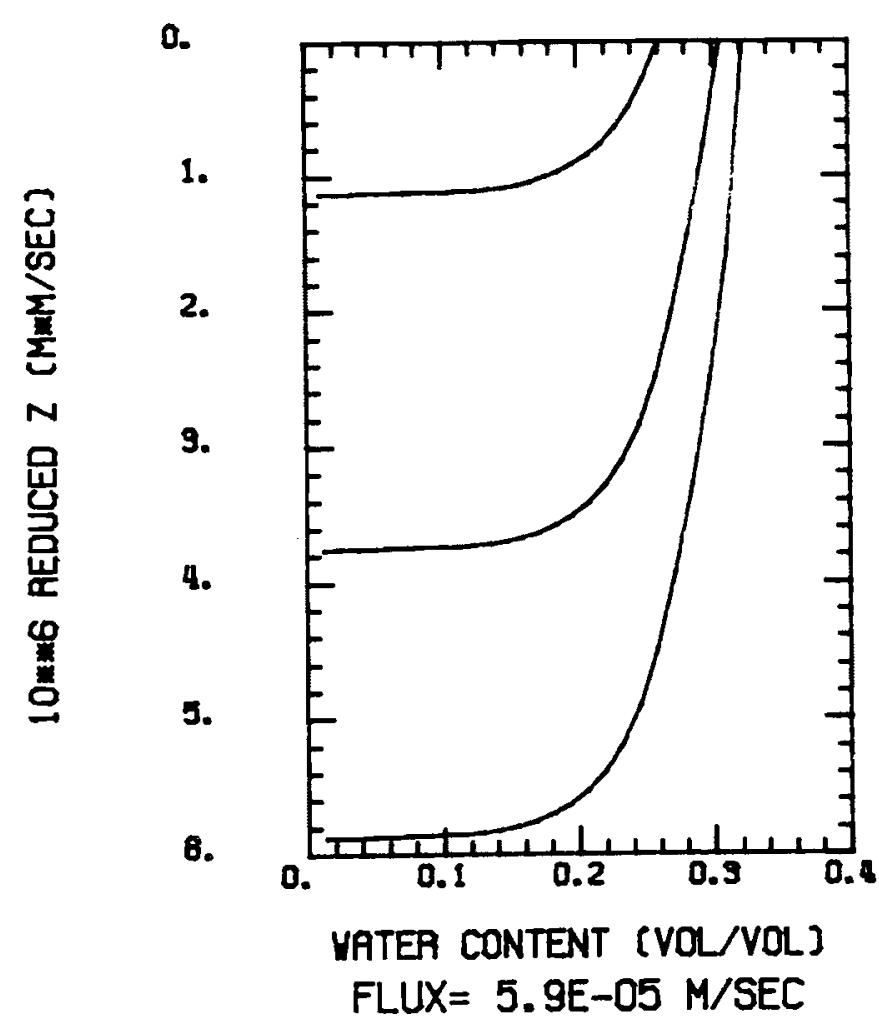

FIGURE 3. Infiltration Profiles at Reduced Times: $2.52,8.0,16.1 \times$ $10^{-7} \mathrm{~m}^{\star} \mathrm{m} / \mathrm{sec}$ for a Fine Sand (Perroux, Smiles and White 1981, Figure 4). Surface flux equals $5.9 \times 10^{-5} \mathrm{~m} / \mathrm{sec}$.

(1981), but the surface-water content and trailing edge for the wetting front show agreement. Absorption results shown in Figure 4 compare well with those of Perroux, Smiles and White (1981). These are cases for which flux is greater than or equal to saturated conductivity, and where infiltration approaches an absorption front.

A water balance based on trapezoidal integration of the water-content profile was used to check accuracy. Thus far, using only 25 depth intervals for $Z$, the largest error in water balance was less than $2 \%$ and was generally less than $1 \%$. An increase in the number of intervals would likely further reduce errors in water balance. 


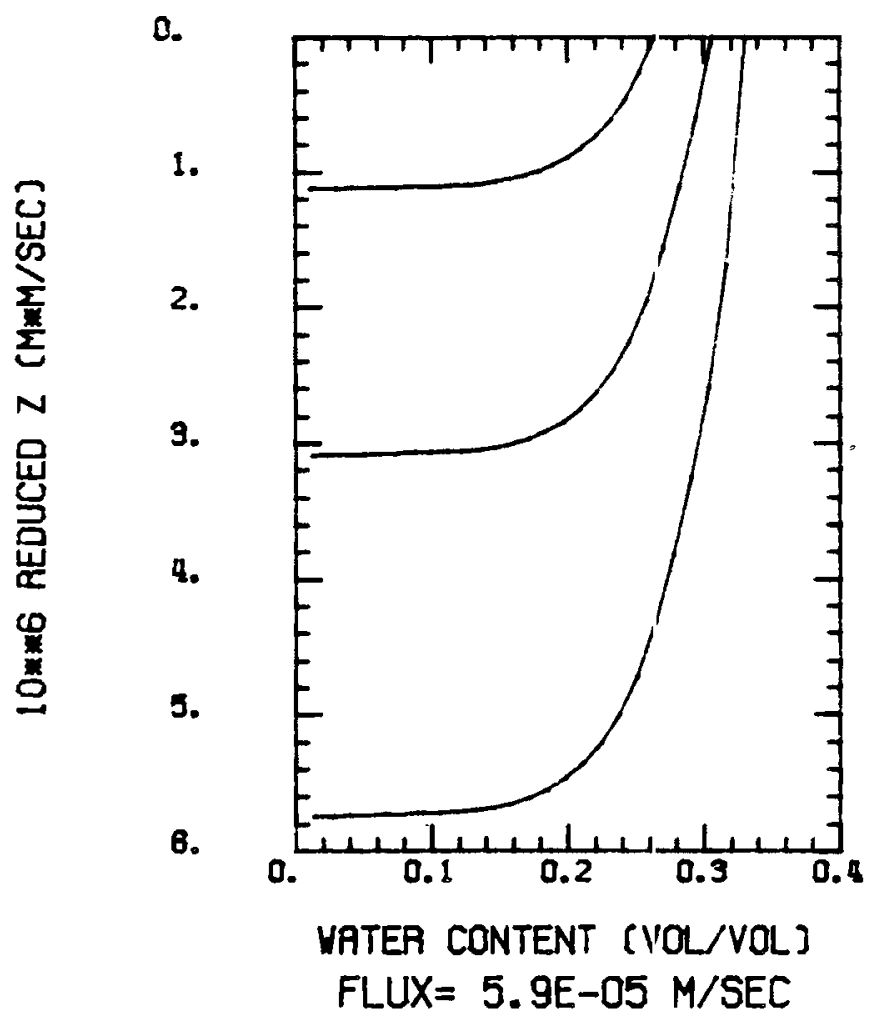

FIGURE 4. Horizontal Absorption Profiles for Values of Figure 3 


\section{RECOMMENDATIONS}

Subjects that deserve further study and some possible changes in the model are

1. Development of a self-contained integration routine to replace the IMSL (1980) routine currently used. A Simpson rule integration should be adequate.

2. Evaluation of other flux-concentration relations for more accurate wetting-front advance. It should be possible to identify parameters that give the best fit of a $F(\hat{\theta})$ function to numerically simulated fronts.

3. Reformulation of surface-flux conditions holding after ponding so that flux can vary depending on ponding depth as a function of time. 


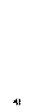




\section{REFERENCES}

Haverkamp, R., et al. 1977. "A Comparison of Numerical Simulation Models for One-Dimensional Infiltration." Soil Sci.Soc. Am. J. 41:285-294.

International Mathematical and Statistical Libraries, Inc. (IMSL). 1980. The IMSL Library Reference Manual. Edition 8. Houston, Texas.

Perroux, K. M., D. E. Smiles, and I. White. 1981. "Water Movement in Uniform Soils During Constant-Flux Infiltration." Soil Sci. Soc. Am. J. $45: 237-240$.

Philip, J. R. 1969. "Theory of Infiltration." Adv. Hydrosci. 5:215-305, Academic Press, N.Y.

Philip, J. R. 1973. "On Solving the Unsaturated Flow Equation: 1. The FluxConcentration Relation." Soil Science 116(5):328-335.

Philip, J. R. 1974. "Recent Progress in the Solution of Non-linear Diffusion Equations." Soil Science 117:257-264.

Philip, J. R., and J. H. Knight. 1974. "On Solving theUnsaturated Flow Equation: 3. New Quasi-analytical Technique." Soil Science 117:1-13.

Prasad, S. N., and M. J. M. Romkens. 1982. "An Approximate Integral Solution of Vertical Infiltration Under Changing Boundary Conditions." Water Resour. Res. 18:1022-1028.

Smiles, D. E., J. H. Knight and K. M. Perroux. 1982. "Absorption of Water by Soil: The Effect of a Surface Crust." Soil Sci. Soc. Am. J. 46:476-481.

White, I., D. E. Smiles and K. M. Perroux. 1979. "Absorption of Water by Soi 1: The Constant Flux Boundary Condition." Soil Sci. Soc. Am. J. 43:659-664 
APPENDIX A

INF IL1D USER'S MANUAL 


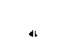

. 
INFILID USER'S MANUAL

The INFILID program solves two integral equations, (7) and (10), to define the position of a wetting front as a function of time for a constant-flux boundary condition. Equation ( 7 ) defines the depth, z, as an integral function of the water content, and Equation (10) defines the time as an integral function of the surface water content. In order to define the wetting front for a specific time, Equation (10) must be solved interatively for various surface water contents until the value corresponding to specified time is found. The INFIL1D program increments the surface water content between the upper and lower limits and solves for the corresponding times. If specific times are required, the surface water content associated with the specified time is interpolated.

INPUT GUIDE FOR PROGRAM INFILID

WRITIEN BY TOM MCKEON AND STEVE SIMMONS

LAST REVISION: $12 / 1982$

THIS PROGRAM IS DESIGNED TO CALCULATE WETTING FRONT MOVEMERT

FOR CONSTANT FLUX BOUNDARY CONDITIONS (ONE DIMENSIONAL)

THE INPUT FILE IS HYDRA. DAT

THE OTPUT FILES INCLUDE;

1) A LINE PRINTER FLOT CALLED THETA. PLT

2) A LISTING OF CALCULATED VALUES WRITTEN TO UNIT 6

3) A PEN PLOTIIER DATA FILE CALLED INFIL. RES, THIS FILE IS FORMAITED AS INPUT TO THPLT.FLX WHICH IS CONIROLLED BY TAPLT.CIL

THE NECESSARY DATA TO RUN INFILID ARE:

VARIABLE NAME

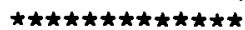

1
DEFINITION

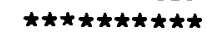

THE NUMBER OF DATA POINTS USED TO TNTERFOLATE DIFEUSIVITY ANJ HYDRAULIC CONDUCTIVTY VALLES
FORMAT

$\star \star \star \star \star \star \star$

FREE FORMAT 
Page 2

$\begin{array}{ll}2 & \text { WC (I=I,NPTS } \\ 3 & \text { HC(I=I,NPTS }) \\ 4 & \text { DF (I=I,NPTS }) \\ 5 & \text { THETAN } \\ 6 & \text { THETAI } \\ 7 & \text { THSAT } \\ 8 & \text { VO } \\ 9 & \text { THLESS } \\ & \\ 10 & \text { NTIME } \\ 11 & \text { NSTEP } \\ 12 & \text { AERR } \\ 13 & \text { RERR }\end{array}$

WATER CONTENT

FREE FORYAT

HYDRAULIC CONDUCTIVITY

DIFFUSIVITY

THE WATER CONTENT AT TIME:=0

A SOIL WATER CONIENT

ARBITRARILY CIOSE TO THET'AN

(THIS IS USED TO AVOID SINGULARITIES)

SATURATED SOIL WATER CONIENT

THE CONSTANT FLUX IMPOSET AT

THE SOIL SURFACE

A SMALI NUMBER SUBTRACTEI FROM

THSAT TO AVOID SINGULARITIES

AS THLESS IS DECREASED THE PROGRAM

WILL EXAMINE GREATER TIMES

NUMBER OF TIME INTERVALS

NUMBER OF SPACE (Z) INTERVALS

THE MAXIMUM ABSOLUTE ERROR IN THE NUMERICAL INTEGRATION

THE RETATTVE ERROR IN THE NUMERICAL INTEGRATION (IF RERR=0.0.1 THEN THE INTECRATTON ROUTINE WILL ATTEMPT TO SOLVE THE INTEGRAL WITHIN AN ACCURACY OF TWO DECIMALS PLACES)

14 TDEVF

FRACTIONAL TIME DEVIATTON; THIS PARAMETER DEFINES THE ACCIJRACY REQUIRED IN THE INTERPOLATION OF S?ECIFIED TIMES

15 IFLAGI

1 OR 2 IF IFLAGI=I THE PROBLEM IS AN INFILTRATION WITH GRAVITY FORMULATION IF IFLAGI=2 THE PROBLEM I: EOPMULATED AS AN ABSORPTION PROBLEM (GRAVITY FREE)

16 IFLAG2

1, 2, OR 3 DETER:IINES THI: TYPE OF APPROXIMATION USED AS THE FUNCTIONAL F

17 IFLAG3

O OR I DETERMINES THE TYI?E OF DATA THAT " " IS PRINTED TO THE PLOTTER INPUT FILE (INFIL.RES) IF IFLAG3 IS O THE ACTUAL CALCULATED DATA POINTS ARE PRINTED IF IFLAG $=1$ THEN DATA POIMTS ARE I INTERPOLATED TO EQUAL INCREMIENTED $Z$ STEPS 
Page 3

EXAMINED (IF TDEVF=0.0 THIS IS NOT REQUIRED)

$19 T(I, I=M)$

SPECIFIC TIMES TO BE EVALUATED

FREE FORMAT

(IF TDEVF=0.0 THIS IS NOT REQUIRED)

20 ZNAX

MAXIMUM DEPTH ( USED WHEN IFLAG =1)

NURBER OF EQUAL SPACED INTERVALS TO INTERPOLATE WATER CONTENT VALUES ( USED WTEEN IFLAG3=1 )

This sample input file was used to generate the test case compared with the results of Haverkamp et al. (1977). The results of this test case are shown in Figure 1.

23,

$.1, .11, .12, .13, .14, .15, .16, .17, .18, .19, .20, .21, .22, .23, .24, .25, .26, .27, .28$ ， $.285, .286, .2864, .287$

$.13307,0.2121, .30634, .418, .5502, .70711, .89434,1.1194,1.3926,1.7284,2.1472$, $2.6794,3.3713,4.2970,5.5814,7.45,10.344,15.218,24.253,31.274,32.761,33.318$, 34.0 ,

$93.55,101.94,112.25,124.75,139.92,158.44,181.3,209.9,246.28,293.49,356.28$, $442.31,564.64,747.03,1036.4,1536.7,2518.8,4902.3,14244 ., 45459 ., 79475$. $.11813 \mathrm{E}+06, .16100 \mathrm{E}+06$

$0.1,0.101,0.287,13.69,0.00001$

20,25

$0.0,0.001,0.01$

$1,3,0$

$4,0.2,0.3,0.4,0.6$,

$0 ., 0$ 
. 
APPENDIX B

PROGRAM LISTINGS 


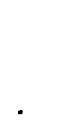




\section{APPENDIX B}

\section{PROGRAM LISTINGS}

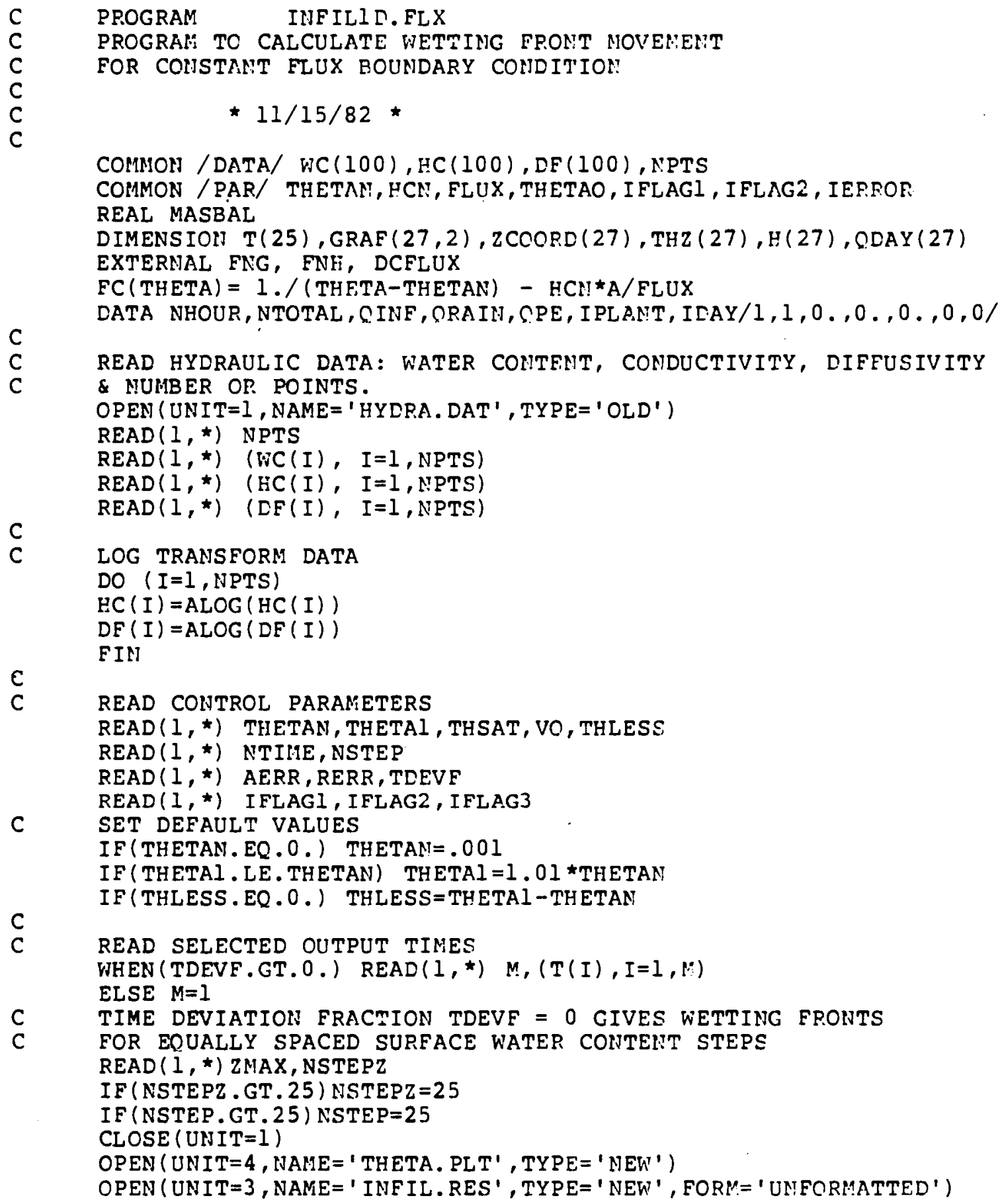


C

C

$I F\left(I F_{\perp i}, G 3, E Q .0\right) \mathrm{ZNAX}=0$.

IF ( ZMAX. EQ .0) NSTEPZ = NSTEP

NPT $=$ NSTEPZ +1

NPTO $=$ NSTE $P+1$

DTIME $=$ NTIME

DEL Z $=$ ZMAX/NSTEPZ

DO $(I=1, N: P T)$

$\operatorname{CRAF}(I, I)=\operatorname{DEL} Z *(I-I)$

FII:

IRITE (3) MPT, I PL NNT, (GR $A F(L L, 1), L I,=1$, I'P'P) , DIIHE

C

C

TEST CALCULATE HYDRAULIC PROPERTIES

DTHETA $=($ THSAT-THETAL $) /$ NSTEP

HCN=FNK $($ THETAN $)$

DFN $=$ FND $($ THETAN $)$

IF (IFLAGI . EQ.1) FLUX $=\mathrm{VO}-\mathrm{HCN}$

IF ( IFLAGL . EQ . 2 ) FLUX $=$ VO

THETAO $=$ THSAT

WRITE $(6, *)$ 'HYDRAULIC PROPERTIES:'

WRITE $(6,904)$

904 FORMAT ( IOX,'STEP', 3X,'THETA',7X,'K(THE'.AA)', 8X, 'D(THETA)')

WRITE $(6, *)$ NSTEP, THETAN, HCN, DFN

DO $(I=1, N S T E P+1)$

THETA $=$ DTHETA * $(I-1)+$ THETAI

WRITE $(6, *)$ I, THETA, FNK (THETA), FND (THETA)

$\operatorname{WRITE}(6, *)$ ' $\mathrm{TNG}(\mathrm{THETA})=$ ', FNG (THETA)

C

FIN

C DETERMINE EXPONENTIAL FORN NEAR INITIAI, VATER CONTENT

$A=($ ALOG (FNK (THETAI) ) -ALOG ( HCNI) ) /(THETAI - THETAN)

$\mathrm{B}=($ ALOG $($ FND $($ THETAI $))-$ ALOG $($ DFN $)) /($ THETAI - THETANT $)$

C

RESTRICT SURFACE WATER CONTENT RANGE ERSED ON FLUX VO AMAY $=$ ALOG $(V O)$

CALL INTERP (HC, WC, NPTS, AMAX, THMAX)

VRITE $(6, *), '$

THMAXO $=$ THMAX - THLESS

IF (VO.GT. FNK (THSAT))

THMAXO $=$ THSAT

IPOND $=1$

FIn]

WRITE $(6, *)$ 'MAX THETA=' , THHAX

$\operatorname{WRITE}(6, *)$ ' APPLIED MAX THETA $=$ ', THMAXO 


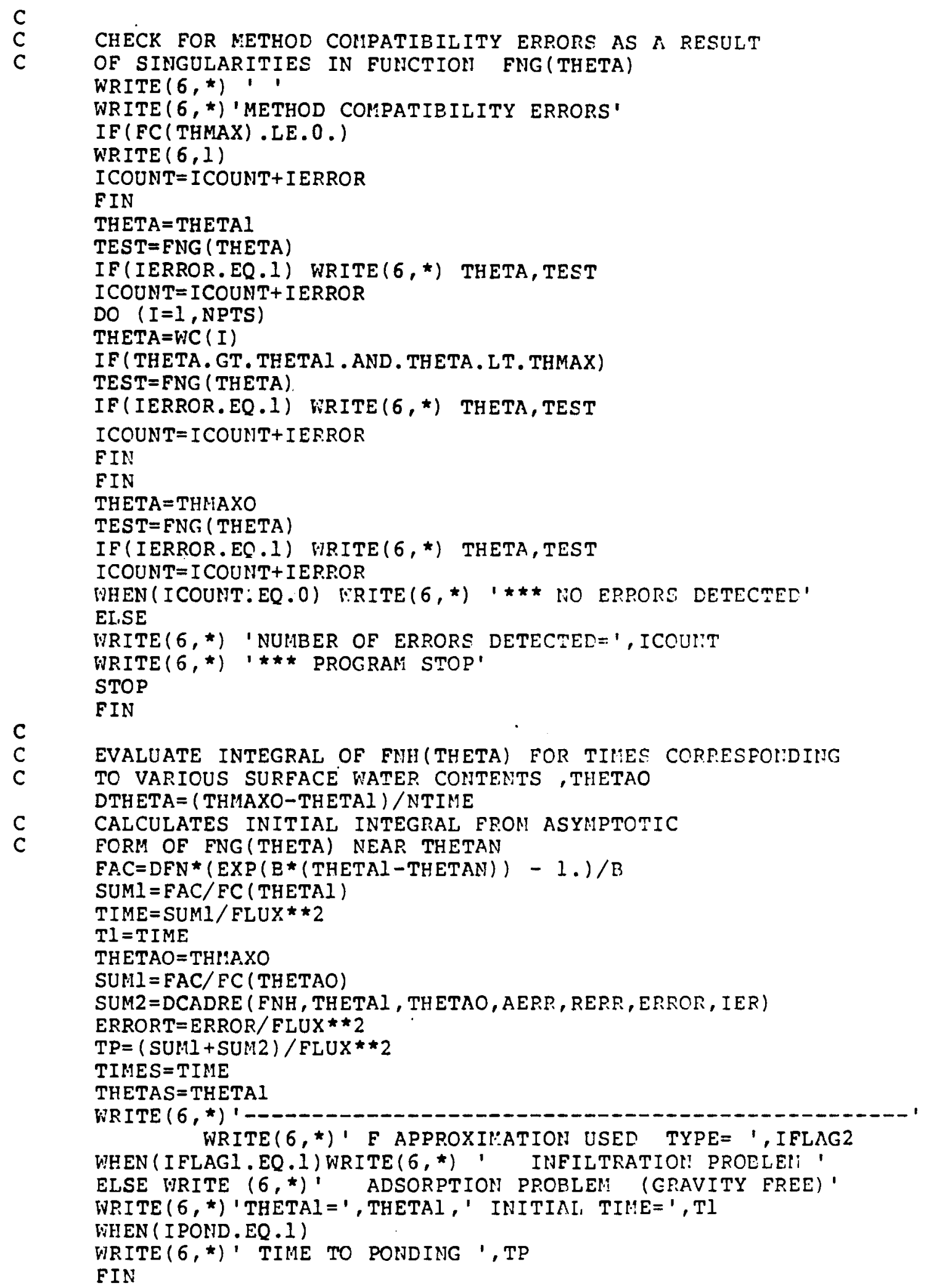




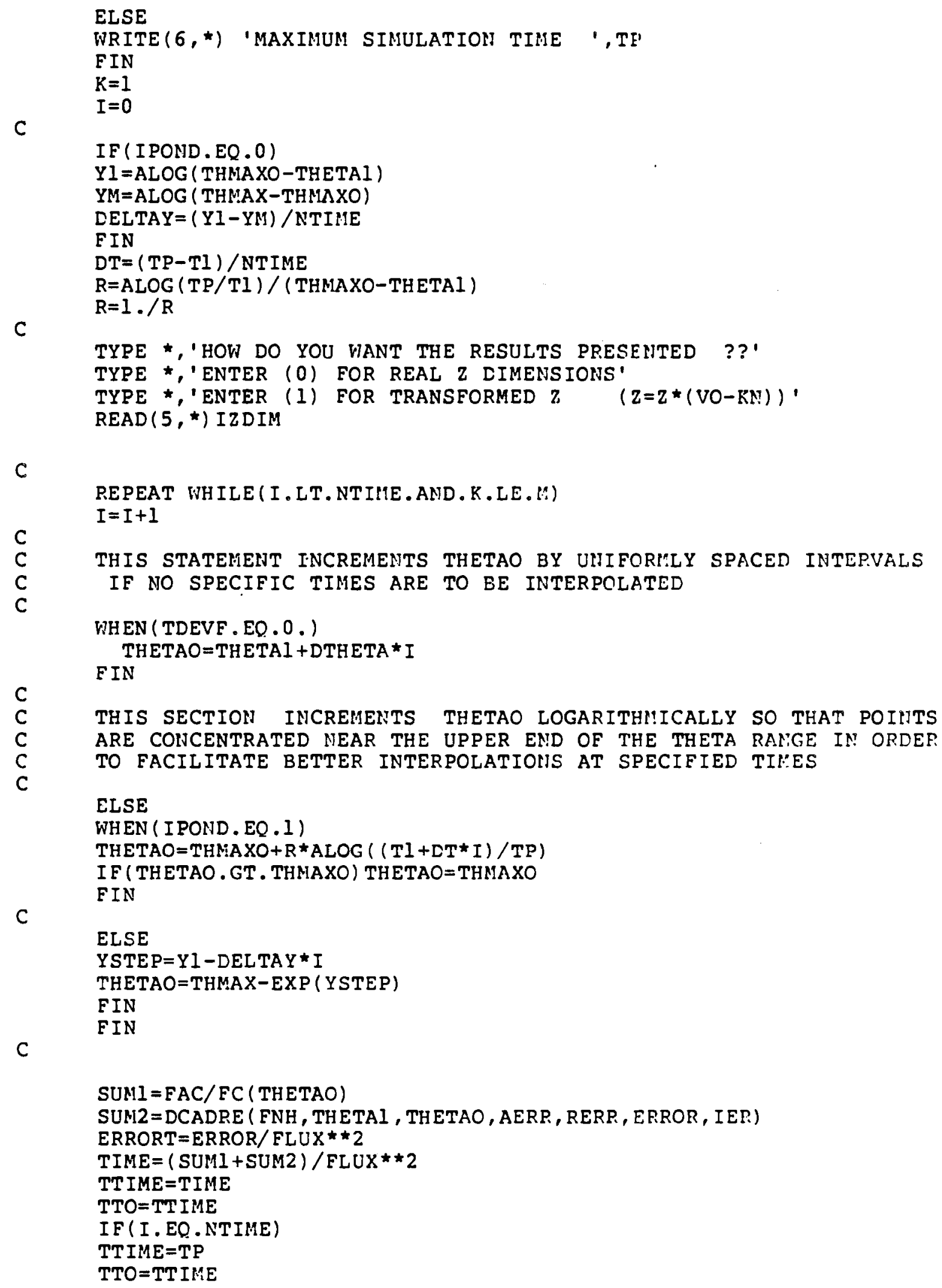




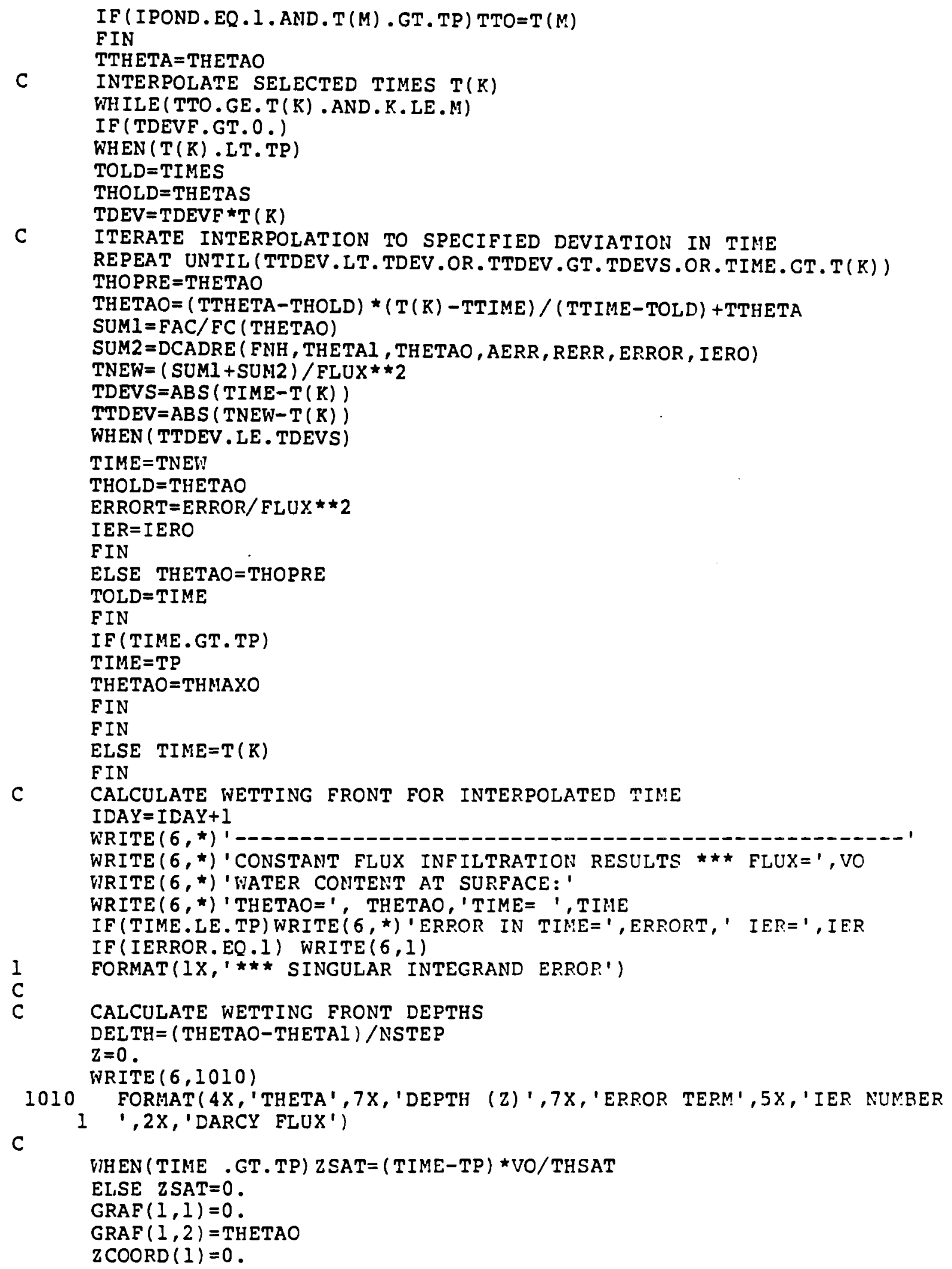




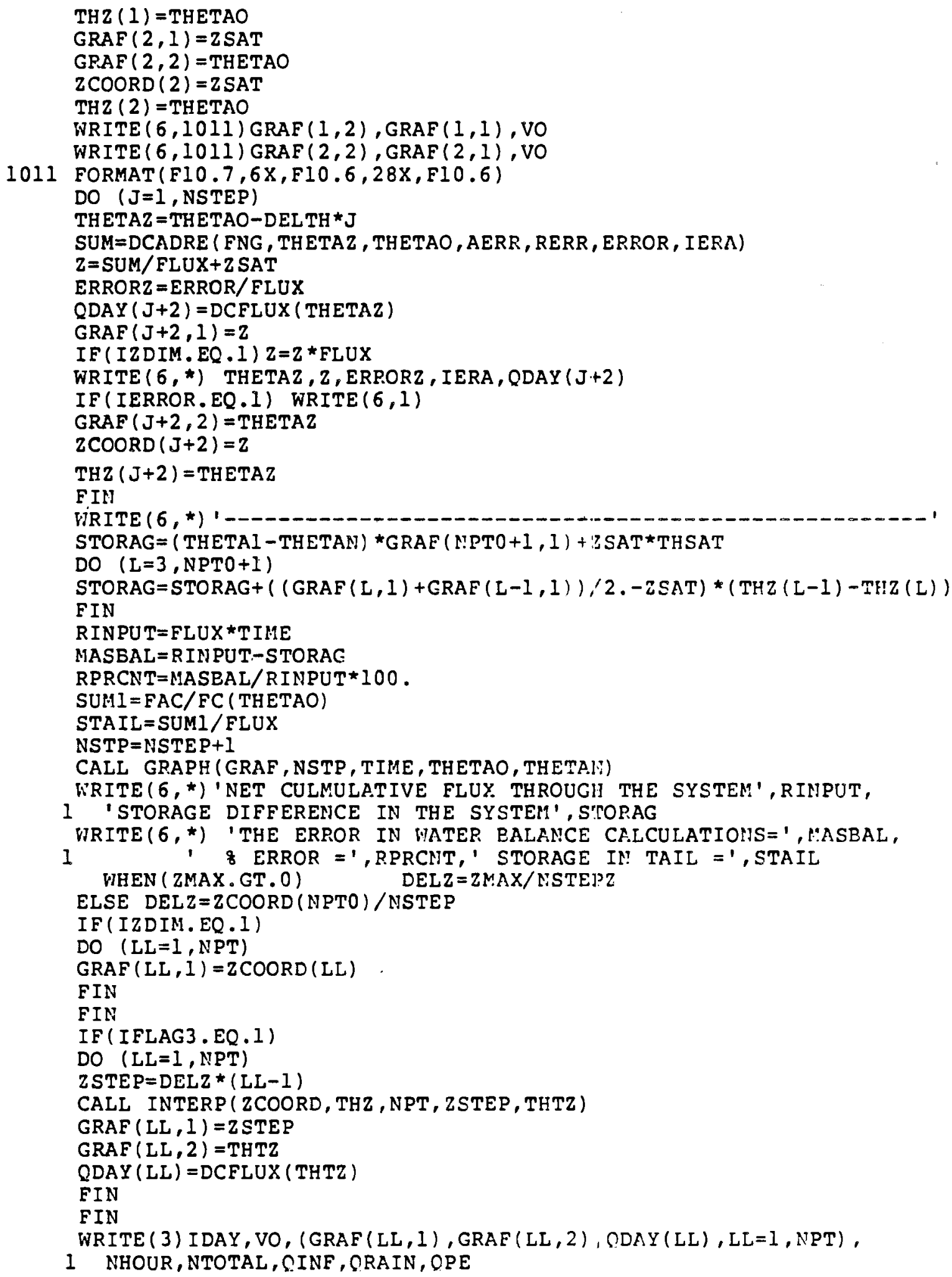




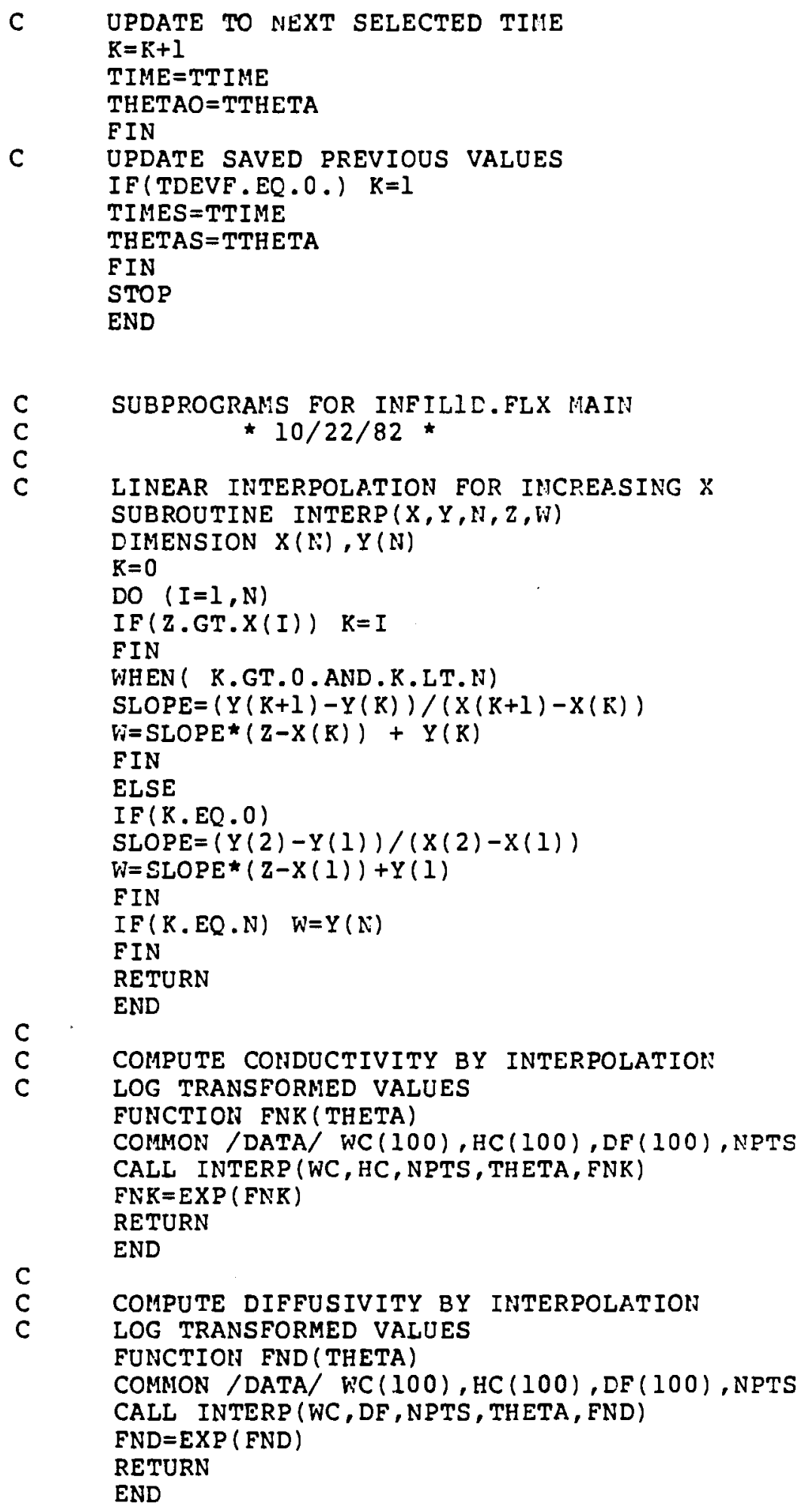


C

FUNCTION FNG (THETA)

COMMON / PAR/ THETAN, HCN, FLUX, THETAO, IFL.$G 1$, IFLAG2, IERROR

IERROR $=0$

PHI $=$ (THETA-THETAN) / (THETAO-THETAN)

CONDITIONAL

(IFLAG2.EQ.1) $\mathrm{F}=\operatorname{SIN}\left(3.141592 / 2 .{ }^{*} \mathrm{PHI}\right.$ * $\left.(3.141592 / 4).\right)$

(IFLAG2.EQ.2) F=PHI **(2.-3.141592/4.)

FIN

( IFLAG2.EQ.3) F=PH I

CONDITIONAL

( IFLAGI.EQ.I) FNG=FND ( THETA) / (F- (FNK (THETA) -HCN) / FLUX)

( IFLAGl . EQ . 2) FNG $=$ FND ( THETA) /F

FIN

IF(FNG.LT.0.) ERROR=1

RETURN

END

C

C COMPUTE THE DARCY FLUX

FUNCTION DCFLUX (THETA)

COMMON / PAR/ THETAN, HCN, FLUX, THETAO, IFLAGI, IFLAG2, IERROR

PHI $=($ THETA-THETAN $) /($ THETAO-THETAN $)$

CONDITIONAL

(IFLAG2.EQ.1) $\mathrm{F}=\operatorname{SIN}\left(3.141592 / 2{ }^{\star} \mathrm{PHI}\right.$ * $(3.141592 / 4$.$) )$

(IFLAG2.EQ.2) $\mathrm{F}=\mathrm{PHI} \star *(2 .-3.141592 / 4$.

FIN

(IFLAG2.EQ.3) $\mathrm{F}=\mathrm{PHI}$

DCFLUX $=(F L U X * F)+H C N$

RETURN

END

FUNCTION FNH (THETA)

COMMON / PAR/ THETAN, HCH, FLUX, THETAO, IFLAGI, IFLAG2, IERROR

FNH $=($ THETA - THETAN $) \star F N G($ THETA $)$

RETURN

END

SUBROUTINE GRAPH(GRAF, NSTEP, TIME, THETAO, THETAN)

DIMENSION GRAF (NISTEP, 2)

DATA DOT, $2 I P / 1 * 1,0.0 \%$

WRITE $(4,909)$ THETAO, TIME

909 FORMAT(' 1 ', ' $\star \star \star 1,20 X, '$ THETA VS. DEPTH $(Z)^{\prime}, '$ THETAO $=1, F 7.4$,

$1 \quad 2 \mathrm{X}, \mathrm{T}^{\mathrm{TIME}}=1, \mathrm{FI} 2.5,1,6 \mathrm{X}, \mathrm{Z}^{\prime}, 1 \star \star \star \prime, 1 \mathrm{X}$

2 '0.0',26x,'0.1',27x,'0.2',27x,'0.3',/,11x,119('-'))

RASIM $=300$ * THETAN

IF ( RASIM. EQ.0) KASIM=1

$\operatorname{RTST}=40 . *(\operatorname{GRAF}(1,1) / \operatorname{GRAF}(\operatorname{NSTEP}, I))$

IF (KTST.GE.2)

$K R=300$. *THETAO

$J=R R-R A S I M-1$

WRITE $(4,24) Z I P, D O T$

FIN

$\mathrm{KZ}=0$ 


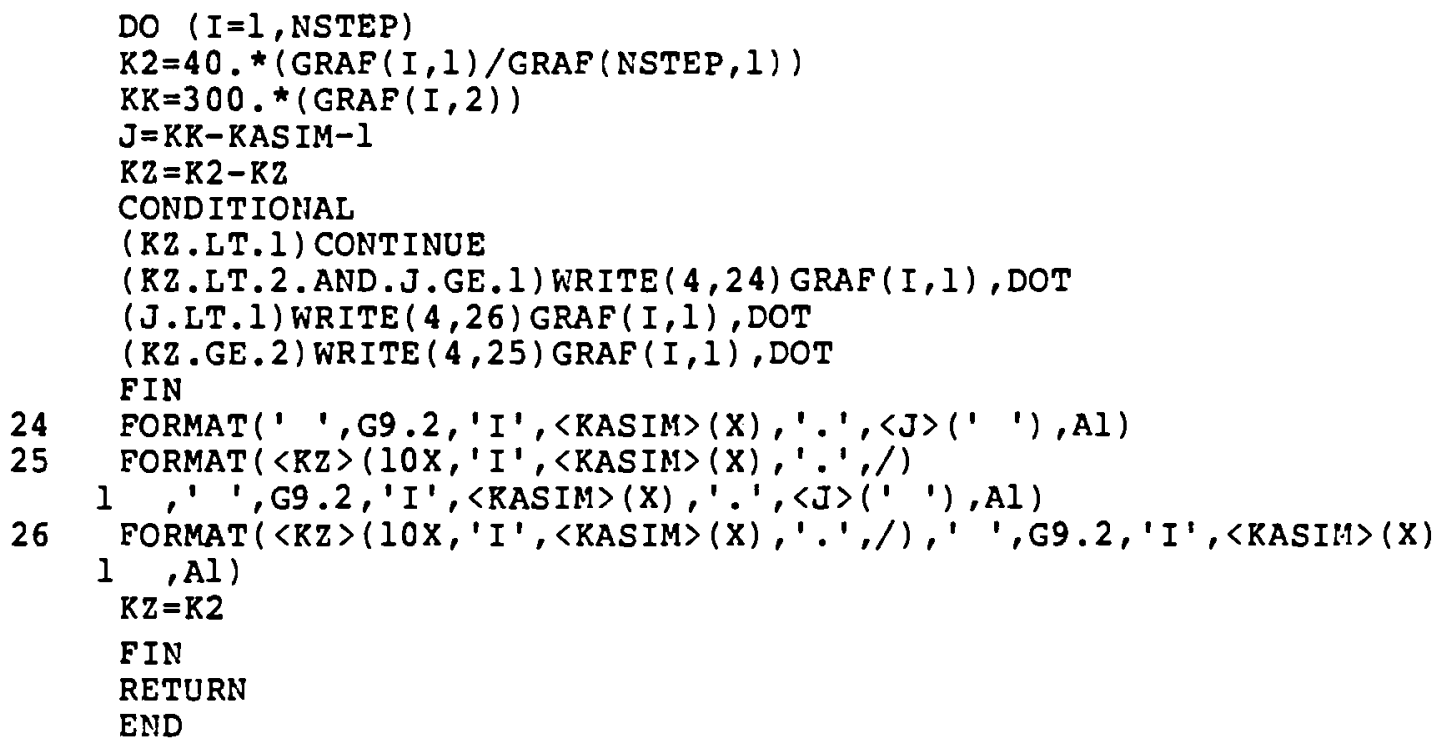




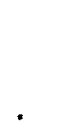

.

. 


\section{$\underline{\text { DISTRIBUTION }}$}

No. of

Copies

OFFSITE

D. E. Large, National

Program Manager

ORO Radioactive Waste

Management Program

Oak Ridge Operations Office

U.S. Department of Energy

P.0. Box E

Oak Ridge, TN 37830

5 L. J. Mezga, Program Manager

Low-Level Waste Management Program

Oak Ridge National Laboratory

P.0. Box X

Oak Ridge, TN 37830

M. J. Barainca, Program Manager

Low-Leve 1 Waste Management

Program

Idaho Operations Office

U.S. Department of Energy

550 Second Street

Idaho Falls, ID 83401

R. Boland

Waste Management Project Office

Nevada Operations Office

U.S. Department of Energy

P. 0. Box 14100

Las Vegas, NV 89114

C. P. Gertz, Chief

Radioactive Waste Technology

Branch

Idaho Operations Office

U.S. Department of Energy

550 Second Street

Idaho Fal1s, ID 83401
No. of

Copies

J. J. Jicha, Director

R\&D and Byproducts Division

DP-123 (GTN)

U.S. Department of Energy

Washington, DC 20545

J. M. McGough, Director

Waste Management and

Transportation Development

Division

Albuquerque Operations Office

U.S. Department of Energy

P.0. Box 5400

Albuquerque, NM 87115

S. Mann, Senior Program Manager

Technical Management Division

Chicago Operations Office

U.S. Department of Energy

9800 S. Cass Avenue

Argonne, IL 60439

H. Saucier

Process and Weapons Division

Savannah River Operations Office

U.S. Department of Energy

P.0. Box A

Aiken, SC 29801

27 Technical Information Center

U.S. Department of Energy

P.0. Box 62

Oak Ridge, TN 37830

C. A. Abrams, Manager of Radiol. Eng.

Argonne National Laboratory West

P.0. Box 2528

Idaho Falls, ID 83401 
No. of

Copies

Technical Library

Argonne National Laboratory

Argonne, IL 60439

B. Rawles

Battelle Memorial Institute

Office of Nuclear Waste

Isolation

505 King Avenue

Columbus, $\mathrm{OH} 43201$

P. Columbo, Group Leader

Nuclear Waste Research

Brookhaven National Laboratory

Building 701

Upton, NY 11973

R. H. Beers, Manager

Waste Management Programs

Division

EG\&G Idaho, Inc.

P.0. Box 1625

Idaho Falls, ID 83415

Program Manager

Low-Level Waste Management

Program

EG\&G Idaho, Inc.

P.0. Box 1625

Idaho Falls, Idaho 83415

G. L. Meyer

Project Leader

LLW Standard

U.S. Environmental Protection Agency

Office of Radiation Programs

ANR-460

Washington, DC 20460

Environmental Protection Agency

Technology Assessment Division Office of Radiation Programs

Washington, DC 20460
No. of

Copies

International Ground Water Modeling Center

Holcorib Research Institute

Butler University

Indianapolis, IN 46208

2 Technical Library

Idaho National Engineering Laboratory

Idaho Falls, ID 83401

T. Harvey

Mai1 istop L-262

Lawrence Livermore National Laboratory

P.0. Box 808

Liverinore, CA 94550

D. T. Oakley

Program Manager for Waste Management

Los Alamos National Laboratory

P.0. Box 1663

Los Alamos, NM 87545

J. G. Steger

Group Leader

Environmental Science (LS-6)

MS K- 495

Los Alamos National Laboratory

P.0. Box 1663

Los Alamos, NM 87544

2 Technical Library

Los Alamos National Laboratory

Los Alamos, NM 87545

National Academy of Sciences

National Research Council

2101 Eonstitution Avenue

Washington, DC 20418

E. F. Conti, Chief

Waste Management Branch

U.S. Nuclear Regulatory Comnission

Mail Stop 1130-SS

Washington, DC 20555 
No.of

Copies

E. O'Donnel1

U.S. Nuclear Regulatory Commission

Mail Stop 1130-SS

Washington, DC 20555

2 NRC Division of Technical

Information and Document Control

U.S. Nuclear Regulatory

Commission

Washington, DC 20555

2 Technical Library

Oak Ridge National Laboratory

Oak Ridge, TN 37830

E. L. Albenesuis

Savannah River Laboratory

P.0. Box A

Aiken, SC 29801

2 Technical Library

Savannah River National Laboratory

Aiken, SC 29801

J. Fischer

Low-Level Radioactive Waste Program

U.S. Geological Survey

Water Resources Division

12201 Sunrise Valley Drive

Reston, VA 22092

V. C. Rogers

Rogers \& Associates Engineering Corporation.

P.0. Box 330

Salt Lake City, UT 84110
No. of

Copies

ONSITE

Hanford Engineering Development Laboratory

R. E. Lerch

2 Richland Operations Office

M. Dayoni

H. E. Ransom

3 Rockwell Hanford Operations

J. F. Albaugh

J. W. Patterson

J. L. Deichman

64 Pacific Northwest Laboratory

C. R. Cole

D. W. Dragnich

M. D. Frestiley

G. W. Gee (10)

P. C. Hays

L. T. Jones

C. T. Kincaid

L. T. Lakey

T. J. McKeon

R. W. Nelson

A. E. Reisenauer

C. S. Simmons (35)

S. W. Tyler

L. L. Wende 11

Technical Information (5)

Publishing Coordination (2) 
.

, 